\title{
Preliminary Numerical Analysis for the Role of Speed onto Laser Technological Processes
}

\author{
Lyubomir Lazov \\ Faculty of Engineering \\ Rezekne Academy of Technologies \\ Rezekne, Latvia \\ lyubomir.lazov@rta.lv \\ Erika Teirumnieka \\ Faculty of Engineering \\ Rezekne Academy of Technologies \\ Rezekne, Latvia \\ erika.teirumnieka@rta.lv
}

\author{
Nikolay Angelov \\ Department of Physics, Chemistry and \\ Ecology \\ Technical University of Gabrovo \\ Gabrovo, Bulgaria \\ angelov_np@abv.bg
}

\author{
Edmunds Teirumnieks \\ Faculty of Engineering \\ Rezekne Academy of Technologies \\ Rezekne, Latvia \\ edmunds.teirumnieks@rta.lv
}

\begin{abstract}
Studying the impact of speed on a number of laser processes such as marking, engraving, cutting, welding and others is crucial for the optimization of these technological processes. The processing speed, along with the frequency of laser pulses and their duration, also determines the time of action in the processing area and hence the absorbed quantity of electromagnetic energy. Based on numerical experiments with specialized software TEMPERATURFELD3D, the report analyzes the temperature variation in the processing area as a function of speed. The researches were analyzed for processing with two types of lasers emitting in the visible and infrared areas of the electromagnetic spectrum and two types of steels (tool and structural). From the course of the obtained temperature fields the dependence of temperature on the speed at two power densities was obtained. The obtained results help to make a preliminary assessment the speed work intervals for the processes as laser marking, laser engraving, laser cutting, laser welding and others. In this way, it is assisted in building an optimal concept for the passing of a particular technological process in function of the laser source, the material and the type of the technological operation.
\end{abstract}

Keywords-laser technological processes, numerical experiments, laser, steel, temperature, speed, power density

\section{INTRODUCTION}

Laser technologies has been undergoing rapid development in recent decades. New types of lasers with high-quality of radiation, high reliability and high efficiency were constructed. This has allowed to be extended the diapason of lasers in many industries spheres. In particular, laser process processes such as marking, engraving, cutting, welding, drilling of holes, tempering, annealing, overlaying, etching, scribing and others are continuously expanding their positions [ 1 - 7]. In addition, the need for systematic analysis and solutions to the engineering problems that arise during their introduction into production increases. In each case, research should be done to optimize the process and to determine the operating intervals of the basic technological parameters
[8-10]. Numerical calculations with appropriate software or real experiments are used. Thus, technological tables for each particular process, type of laser and material can be obtained.

The purpose of the publication is to study the influence of velocity at constant power densities for $\mathrm{CuBr}$ laser and fiber laser on samples of structural steel for basic technological processes (marking, cutting, welding, engraving).

Studies will be conducted in the following areas:

- Receiving temperature fields in the laser impact area for different speeds and power densities for samples of steels C35 and 50G;

- Analysis of graphical dependencies of temperature from speed for two power densities for the investigated lasers and materials.

- Evaluating the results from the perspective of the materials surveyed;

- Assessment of the role of processing with both types of lasers - $\mathrm{CuBr}$ laser and fiber laser;

- Determination of working intervals of processing speed for two fixed power densities to achieve the desired temperature regimes.

\section{EXPOSITION}

Laser technology processes are complex and their implementation depends on many factors. Factors influencing laser technological processes can be grouped into three groups (Figure 1) associated with:

- properties of the material - optical properties (reflection coefficient, absorption capacity, absorption coefficient, depth of penetration) and thermo-physical properties of the material (coefficient of thermal conductivity, specific heat capacity, coefficient of thermal diffusivity, heat diffusion length);

- laser source - laser beam wavelength, laser beam quality, laser beam power, power density, frequency, pulses duration, impulse energy, 
impulse power;

- technological process - speed, step, defocusing, number of repetitions.

These basic factors are within certain physical dependencies. They are important for understanding the physical essence of processes $[8,9]$.

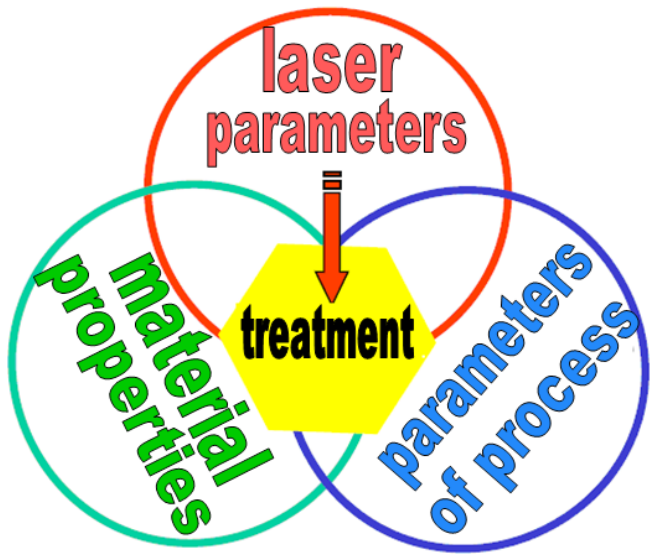

Fig. 1. Basic groups of factors that affect of laser technological processes

The speed $v$ is one of the most important parameters of the technological processes. The time of impact on the sample and the energy that is absorbed in the material in the impact area, depends from its.

For example, the energy $E$ absorbed in the impact area - a square with a side $d$ ( $d$ is diameter of the working spot) is directly related to the processing speed

$$
E=\frac{A P d}{v},
$$

where $A$ is the absorption capacity of the material, $P$ - power of laser radiation.

The speed of technological processes can be consider in several aspects: on the one hand, the speed should be such that the technological process itself takes place at the maximum possible high performance and efficiency; on the other hand, it must be optimal for the technological process within the quality criteria. Between these two trends, a balance must be found in order to obtain optimal technological parameters to achieve good product quality.

Power density and speed are basic magnitudes that influence technological processes. They are related to the temperature of the material surface in the impact area.

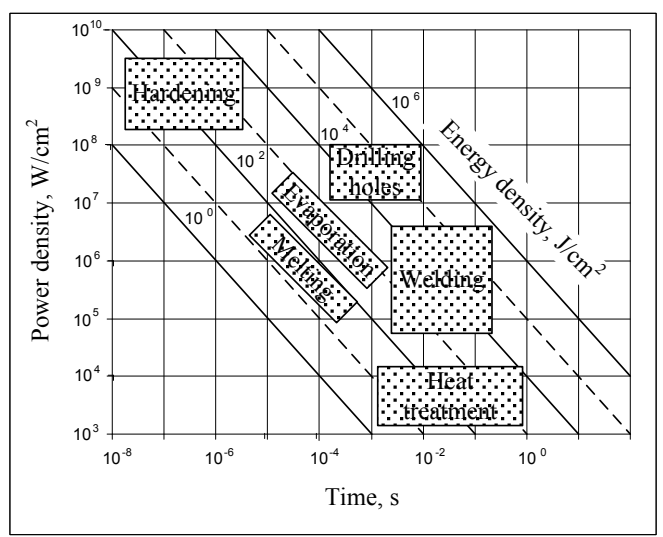

Fig. 2. Relationship between power density and time for some technological processes

The phenomenological (thermophysical) approach to laser exposure to materials requires determining the optimum temperature for each process. As can be seen from Fig. 2, it depends mainly on two factors: the power density

$$
q_{s}=P / S
$$

where $S$ is the area at which it is absorbed by the surface of the material, and time of impact $t$.

The ratio between temperature $T$ and the power density $q_{S}$ can be determined by the thermal conductivity equation

$$
\frac{\partial T}{\partial t}-a \Delta T=\frac{Q(x, y, z)}{\rho c}
$$

where $\Delta=\frac{\partial^{2}}{\partial x^{2}}+\frac{\partial^{2}}{\partial y^{2}}+\frac{\partial^{2}}{\partial z^{2}}$ is the operator of

Laplace, $Q(x, y, z)$ - volume density of the absorbed light flux, $a$ - coefficient of thermal conductivity, $\rho$ density, $c$ - specific heat capacity.

To solve equation (2) it is necessary to set 1 initial condition, 6 boundary conditions and determine $Q(x, y, z)$.

$$
T=f\left[\begin{array}{c}
A q \\
\rho, c, a, R, \alpha \\
x, y, z, t
\end{array}\right]
$$

The heat conduction equation has no analytical solution and numerical methods are used to obtain the temperature fields in the laser impact area. In addition, numerical experiments with the appropriate software should take into account the temperature dependencies of the coefficient of heat conductivity, the specific heat capacity and the coefficient of thermal difusivity.

\section{A. Software}

A program TEMPERATURFELD3D is used to conduct numerical experiments [11]. It specializes in calculating temperature fields for laser impact on various materials. It is suitable for technological processes laser marking, laser engraving, laser cutting, laser welding, laser drilling and others. The dynamic model of the program is chosen for the laser marking process. The main program window then opens (Fig. 3). There is a possibility to store data and results from previous numerical experiments. 


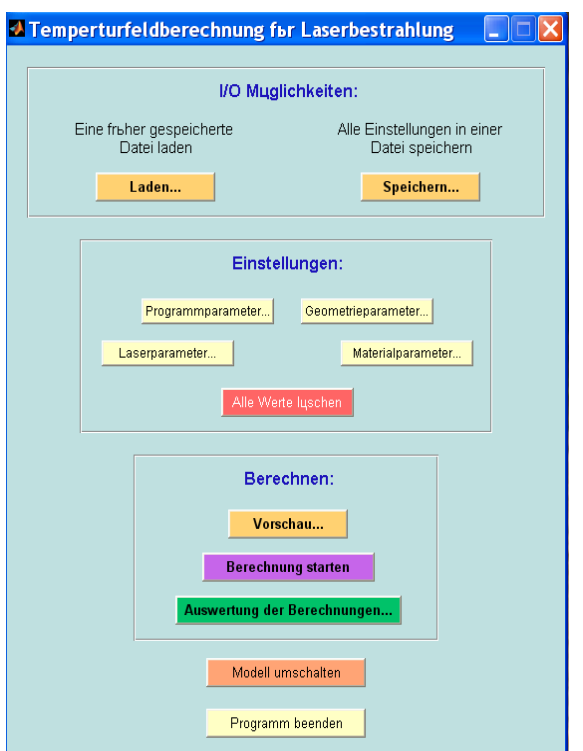

Fig. 3. Basic window of the software Temperaturfeld3D

When performing a specific numerical experiment input data is entered:

- Program parameters;

- Geometric parameters;

- Laser parameters and process parameters;

- Material parameters.

The next step is to perform the calculation. The obtained results can be displayed after opening the „Output Data" window. It includes (Fig. 4):

- Approximating the results;

- Animation of the whole process;

- Temperature profile of the material at a time;

- Profile of maximum temperature;

- Dependence of temperature from time;

- Temperature change in depth of the material.

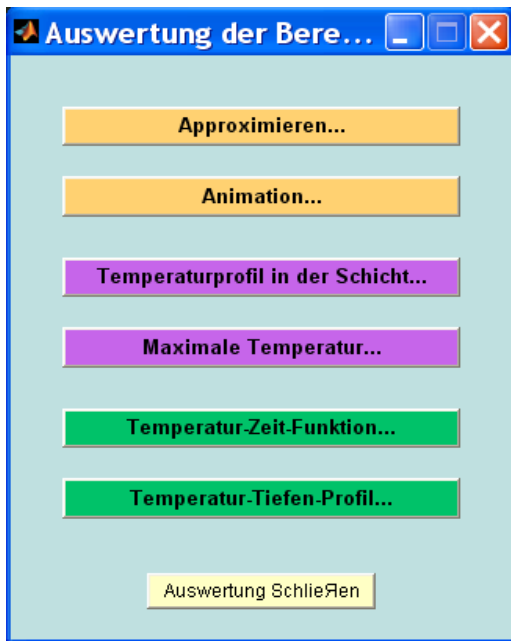

Fig. 4. Window „Output Data“ of the software Temperaturfeld3D

\section{B. Laser technological systems}

The researches concerns for two technological systems with $\mathrm{CuBr}$ laser and fiber laser [12 - 14]. The first laser generates radiation in the visible area and the second laser in the near infrared area. Both lasers work in pulse mode. The $\mathrm{CuBr}$ laser has a very high impulse power, and the fiber laser has a very high beam quality (near the ideal) and a high efficiency. Laser systems have high positioning accuracy and good repeatability. They maintain robust process parameters throughout the entire production process.

Table I. Basic Parameters Of Technological Systems With Cubr LASER AND Fiber LASER

\begin{tabular}{|l|l|l|}
\hline \multicolumn{1}{|c|}{ Laser } & CuBr laser & Fiber laser \\
\hline Wavelength $\lambda, \mu \mathrm{m}$ & 0,511 & 1,062 \\
\hline Power $P, \mathrm{~W}$ & 20,0 & 40,0 \\
\hline Frequency $v, \mathrm{kHz}$ & 20,0 & 20 \\
\hline Pulse duration $\tau, \mathrm{ns}$ & 30 & 250 \\
\hline Pulse energy $E_{\mathrm{p}}, \mathrm{mJ}$ & 1,00 & 2,00 \\
\hline Pulse power $P_{\mathrm{p}}, \mathrm{kW}$ & 33,3 & 8,00 \\
\hline Beam quality $M^{2}$ & $<1,7$ & $<1,1$ \\
\hline Positioning accuracy, $\mu \mathrm{m}$ & 2,5 & 2,5 \\
\hline Efficiency, $\%$ & 10 & 40 \\
\hline
\end{tabular}

\section{Materials}

Numerical experiments are for structural steels C35 and 50G [15]. From structural steel C35 are produced axles, cylinders, crankshafts, washers, spindles, sprockets, rods, wheels, sleepers, shafts, seals, discs and other low strength items that experience small mechanical stresses. The structural alloy steel 50G is used to make friction discs, shafts, sprockets, splines, washers, displacement rollers, bearing bushings, elbows, spindles, flywheel wheels, crankshafts of diesel engines and gas engines, and other details that require increased strength and durability [15]. Both steels have high coefficients of thermal conductivity and thermal diffusivity.

table II. Temperature Dependence Of Certain Parameters Of Construction Steel C35.

Legend: $k$ - coefficient of thermal conductivity, $\rho$ - density, $c$ - specific heat capacity, $a$ - coefficient of thermal diffusivity.

\begin{tabular}{|c|c|c|c|c|}
\hline $\boldsymbol{T}, \mathbf{K}$ & $\begin{array}{c}\boldsymbol{k}, \mathbf{W} / \\
(\mathbf{m} \cdot \mathbf{K})\end{array}$ & $\rho, \mathrm{kg} / \mathrm{m}^{\mathbf{3}}$ & $\mathbf{c}, \mathbf{J} / \mathbf{( k g . K )}$ & $\mathbf{a}, \mathbf{m}^{2} / \mathbf{s}$ \\
\hline 293 & 50 & 7826 & 453 & $1,41.10^{-5}$ \\
\hline 373 & 49 & 7804 & 469 & $1,34.10^{-5}$ \\
\hline 473 & 49 & 7771 & 490 & $1,29.10^{-5}$ \\
\hline 573 & 47 & 7737 & 511 & $1,19.10^{-5}$ \\
\hline 673 & 44 & 7700 & 532 & $1,07.10^{-5}$ \\
\hline 773 & 41 & 7662 & 553 & $9,68.10^{-6}$ \\
\hline 873 & 38 & 7623 & 578 & $8,62.10^{-6}$ \\
\hline 973 & 35 & 7583 & 611 & $7,55.10^{-6}$ \\
\hline 1073 & 29 & 7600 & 708 & $5,39.10^{-6}$ \\
\hline 1173 & 28 & 7549 & 699 & $5,30.10^{-6}$ \\
\hline
\end{tabular}

table III. Temperature Dependence Of Certain Parameters Of Construction Alloy Steel 50G.

\begin{tabular}{|c|c|c|c|c|}
\hline $\boldsymbol{T}, \mathbf{K}$ & $\begin{array}{c}\boldsymbol{k}, \mathbf{W} / \\
(\mathbf{m} \cdot \mathbf{K})\end{array}$ & $\rho, \mathrm{kg} / \mathrm{m}^{\mathbf{3}}$ & $\mathbf{c}, \mathbf{J} / \mathbf{( k g . K )}$ & $\mathbf{a}, \mathbf{~ m}^{2} / \mathbf{s}$ \\
\hline 293 & 43 & 7810 & 477 & $1,15.10^{-5}$ \\
\hline 373 & 42 & 7776 & 487 & $1,09.10^{-5}$ \\
\hline 473 & 41 & 7745 & 500 & $1,06.10^{-5}$ \\
\hline 573 & 38 & 7714 & 517 & $9,52.10^{-6}$ \\
\hline 673 & 36 & 7681 & 533 & $8,79.10^{-6}$ \\
\hline 773 & 34 & 7648 & 559 & $7,95.10^{-6}$ \\
\hline 873 & 31 & 7615 & 584 & $6,97.10^{-6}$ \\
\hline 973 & 29 & 7582 & 609 & $6,28.10^{-6}$ \\
\hline 1073 & 28 & 7577 & 676 & $5,47.10^{-6}$ \\
\hline
\end{tabular}




\section{Numerical experiments}

Multiple numerical experiments were conducted to determine the temperature fields in the impact area for the two lasers and the two steels. The speed varied within the interval $v \in[20 ; 110] \mathrm{mm} / \mathrm{s}$ with step $10 \mathrm{~mm} / \mathrm{s}$ as the power density maintained constant. In the first series of experiments is $q_{\mathrm{S} 1}=9,35.10^{10} \mathrm{~W} / \mathrm{m}^{2}$, and in the second $-q_{\mathrm{S} 2}=1,08.10^{11} \mathrm{~W} / \mathrm{m}^{2}$. The temperature dependence of some parameters of steels (according to Table II and Table III) is recorded. In Fig. 4 shows temperature fields in the impact area for structural carbon steel C35 Both temperatures in the central processing area are higher than the melting temperature.

a)

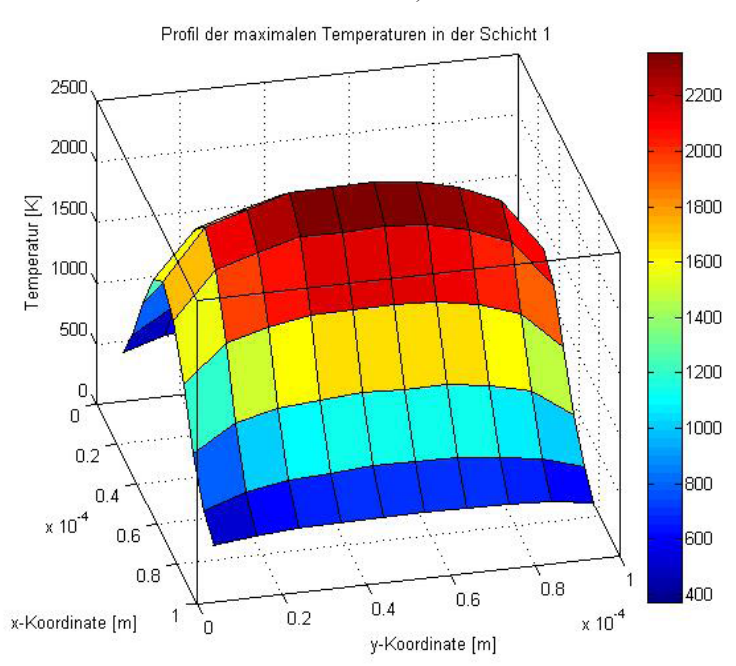

b)

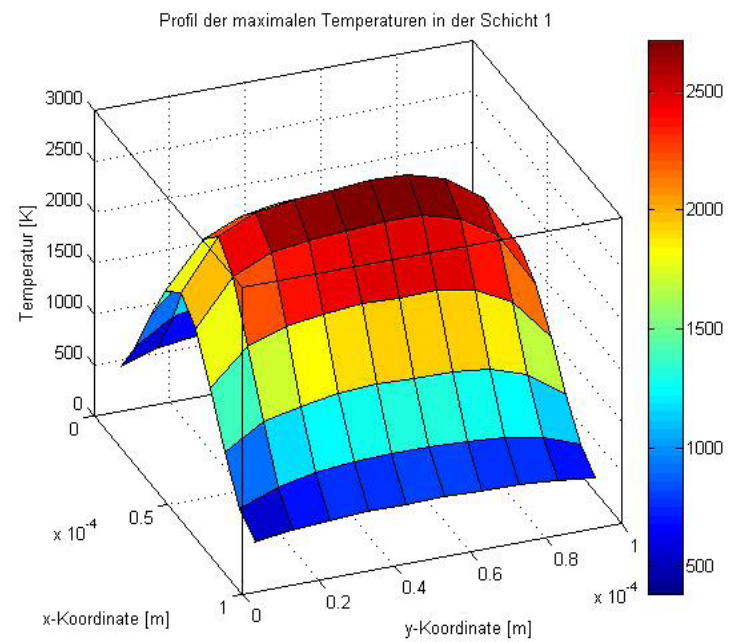

Fig. 5. Температурно поле на образец от конструкционна стомана $\mathrm{C} 35$ за скорост $v=60 \mathrm{~mm} / \mathrm{s}$ и плътности на мощността: а) $q_{\mathrm{S} 1}$ $=9,35 \cdot 10^{10} \mathrm{~W} / \mathrm{m}^{2}$; b) $q_{\mathrm{S} 2}=1,08 \cdot 10^{11} \mathrm{~W} / \mathrm{m}^{2}$

\section{for $\mathrm{CuBr}$ laser}

In Fig. 6 and Fig. 7 are presented graphics of the dependencies of the temperature from the speed for steels $\mathrm{C} 35$ and $50 \mathrm{G}$. From the obtained results, the following conclusions can be drawn:

- The temperature decreases non-linearly with increasing of speed throughout the entire study interval for both steels;

- $\quad$ The temperature reduction rate for steel C35 is

\begin{tabular}{|c|c|c|}
\hline \multicolumn{3}{|c|}{ with CuBr laser for steel C35 } \\
\hline $\boldsymbol{v}, \mathbf{~ m m} / \mathbf{s}$ & $\boldsymbol{q}, \mathbf{W} / \mathbf{m}^{\mathbf{2}}$ & $\begin{array}{c}\Delta \mathrm{T} / \boldsymbol{\Delta} \boldsymbol{v}, \mathrm{K} / \\
(\mathrm{mm} / \mathrm{s})\end{array}$ \\
\hline $20 \div 30$ & $9,35.10^{10}$ & $\mathbf{2 3 , 5}$ \\
\hline $20 \div 30$ & $1,08.10^{11}$ & $\mathbf{2 7 , 0}$ \\
\hline $60 \div 110$ & $9,35.10^{10}$ & $\mathbf{1 5 , 7}$ \\
\hline $60 \div 110$ & $1,08.10^{11}$ & 18,0 \\
\hline \multicolumn{3}{|c|}{ with CuBr laser for steel 50G } \\
\hline $20 \div 30$ & $9,35.10^{10}$ & $\mathbf{2 0 , 6}$ \\
\hline $20 \div 30$ & $1,08.10^{11}$ & $\mathbf{2 3 , 7}$ \\
\hline $60 \div 110$ & $9,35.10^{10}$ & $\mathbf{1 3 , 7}$ \\
\hline $60 \div 110$ & $1,08.10^{11}$ & $\mathbf{1 5 , 8}$ \\
\hline
\end{tabular}

- For structural carbon steel C35, the temperature is about $14 \%$ greater than for structural alloy steel 50G. The reasons for this are the higher absorption of steel $50 \mathrm{G}$.

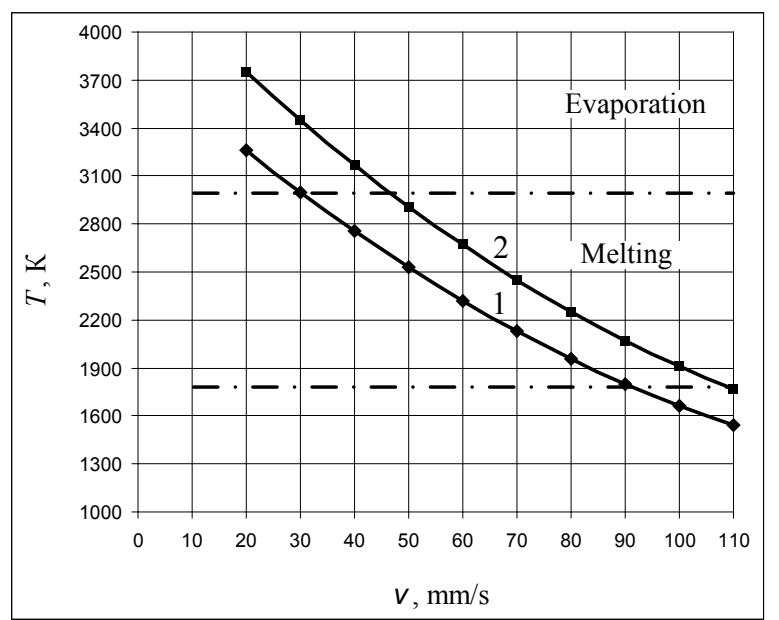

Fig. 6. Graphics of dependence of temperature from speed for structural carbon steel C35 for power density: $1-q_{\mathrm{S} 1}=9,35.10^{10} \mathrm{~W} /$ $\mathrm{m}^{2} ; 2-q_{\mathrm{S} 2}=1,08 \cdot 10^{11} \mathrm{~W} / \mathrm{m}^{2}$.

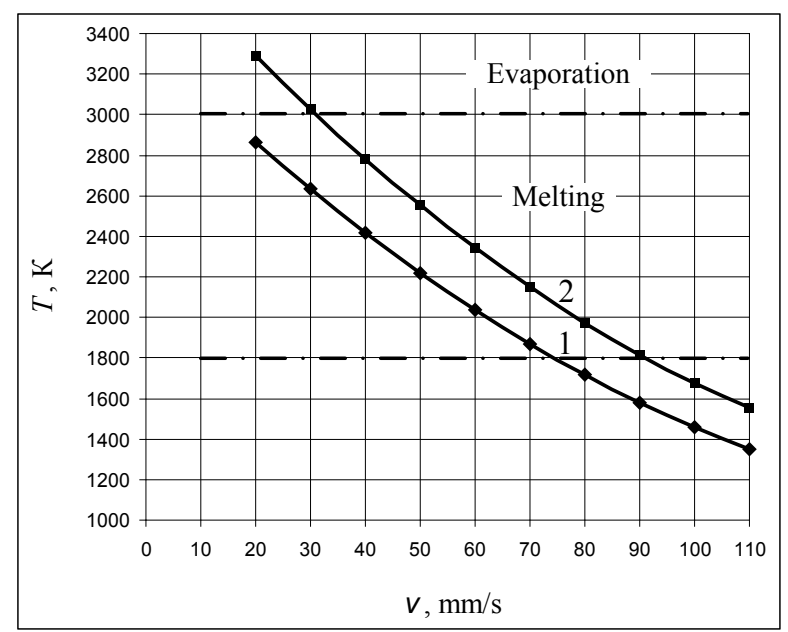

Fig. 7. Graphics of dependence of temperature from speed for structural alloy steel $50 \mathrm{G}$ for power density: $1-q_{\mathrm{S} 1}=9,35.10^{10} \mathrm{~W} /$ $\mathrm{m}^{2} ; 2-q_{\mathrm{S} 2}=1,08.10^{11} \mathrm{~W} / \mathrm{m}^{2}$.

for fiber laser

In Fig. 8 and Fig. 9 are presented graphics of the 
dependencies of the temperature from the speed for steels C35 and 50G. From the obtained graphics, it follows:

- The temperature decreases non-linearly with increasing of speed throughout the entire study interval for both steels;

- $\quad$ The temperature reduction rate for steel C35 is

\begin{tabular}{|c|c|c|}
\hline \multicolumn{3}{|c|}{ with fiber laser for steel C35 } \\
\hline $\boldsymbol{v}, \mathbf{~ m m} / \mathbf{s}$ & $\boldsymbol{q}, \mathbf{W} / \mathbf{m}^{\mathbf{2}}$ & $\Delta \mathrm{T} / \boldsymbol{\Delta} \boldsymbol{v}, \mathrm{K} /(\mathrm{mm} / \mathrm{s})$ \\
\hline $20 \div 60$ & $1,16.10^{11}$ & $\mathbf{2 6 , 3}$ \\
\hline $20 \div 60$ & $1,36.10^{11}$ & $\mathbf{3 0 , 0}$ \\
\hline $60 \div 110$ & $1,16.10^{11}$ & $\mathbf{1 8 , 4}$ \\
\hline $60 \div 110$ & $1,36.10^{11}$ & $\mathbf{2 6 , 2}$ \\
\hline \multicolumn{3}{|c|}{ with fiber laser for steel $\mathbf{5 0 G}$} \\
$20 \div 60$ & $1,16.10^{11}$ & $\mathbf{2 2 , 6}$ \\
\hline $20 \div 60$ & $1,36.10^{11}$ & $\mathbf{2 6 , 3}$ \\
\hline $60 \div 110$ & $1,16.10^{11}$ & $\mathbf{1 5 , 5}$ \\
\hline $60 \div 110$ & $1,36.10^{11}$ & $\mathbf{1 8 , 0}$ \\
\hline
\end{tabular}

- For structural carbon steel C35, the temperature is about $14 \%$ greater than for structural alloy steel $50 \mathrm{G}$.

- For the same speeds and power densities, the sample temperature in the impact area for $\mathrm{CuBr}$ laser is higher than that for fiber laser.. Higher values of temperatures for the $\mathrm{CuBr}$ laser compared to the fiber laser are because the radiation in visible area is better absorbed from the steels from that in the near-infrared area;

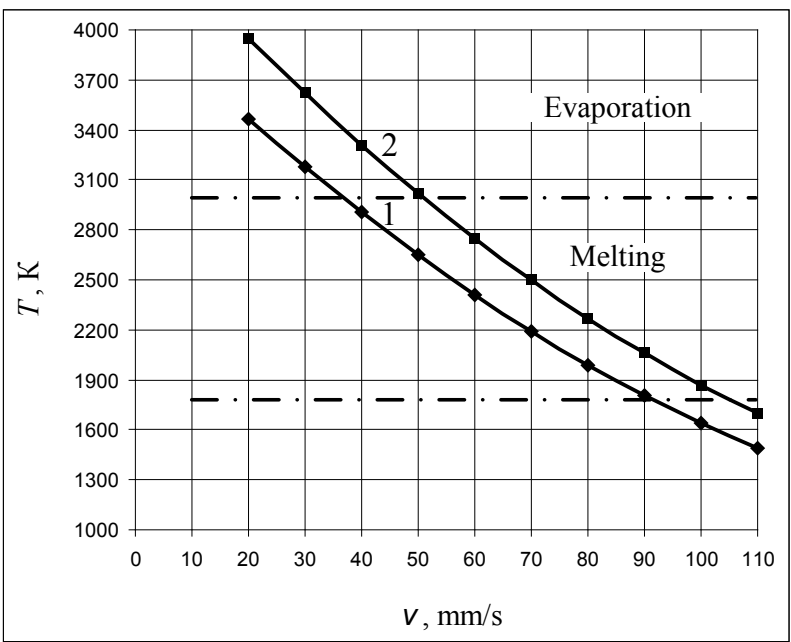

Fig. 8. Graphics of dependence of temperature from speed for structural carbon steel C35 for power density: $1-q_{\mathrm{S} 1}=1,16.10^{10} \mathrm{~W} /$ $\mathrm{m}^{2} ; 2-q_{\mathrm{s} 2}=1,36.10^{11} \mathrm{~W} / \mathrm{m}^{2}$.

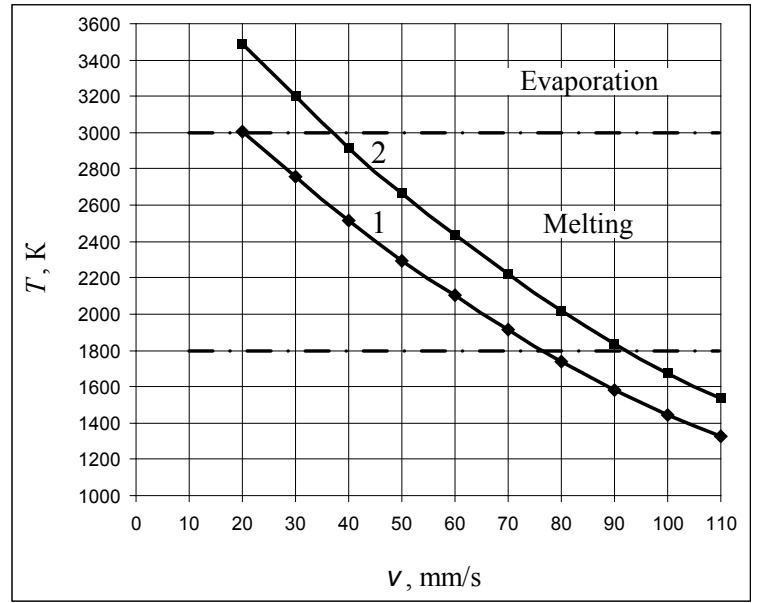

Fig. 9. Graphics of dependence of temperature from speed for structural alloy steel $50 \mathrm{G}$ for power density: $1-q_{\mathrm{S} 1}=1,16.10^{11} \mathrm{~W} /$ $\mathrm{m}^{2} ; 2-q_{\mathrm{S} 2}=1,36.10^{11} \mathrm{~W} / \mathrm{m}^{2}$.

E. Preliminary working intervals of speed

For the realization of the processes marking by melting and welding, the temperature of the sample in the impact zone must be between the melting point and the evaporation temperature. For process processes marking by evaporation, engraving and cutting, the temperature in the impact zone must be higher than the temperature of evaporation.

From the obtained results, preliminary working intervals of the speed for marking by melting and welding were determined (see Fig. 5 - 9):

\begin{tabular}{|c|c|c|c|}
\hline \multicolumn{2}{|c|}{$\begin{array}{c}\text { with } \mathrm{CuBr} \text { laser } \\
\text { for steel C35 }\end{array}$} & \multicolumn{2}{|c|}{$\begin{array}{l}\text { with fiber laser } \\
\text { for steel C35 }\end{array}$} \\
\hline$v, \mathrm{~mm} / \mathrm{s}$ & $q, \mathrm{~W} / \mathrm{m}^{2}$ & $\begin{array}{c}\mathrm{V}, \\
\mathrm{mm} / \mathrm{s}\end{array}$ & $q, \mathrm{~W} / \mathrm{m}^{2}$ \\
\hline $30 \div 90$ & $9,35 \cdot 10^{10}$ & $35 \div 84$ & $1,16.10^{10}$ \\
\hline $47 \div 105$ & $1,08.10^{11}$ & $\begin{array}{c}\mathbf{4 7} \\
\div 105\end{array}$ & $1,36.10^{11}$ \\
\hline \multicolumn{2}{|c|}{$\begin{array}{c}\text { with } \mathrm{CuBr} \text { laser } \\
\text { for steel } 50 \mathrm{G}\end{array}$} & \multicolumn{2}{|c|}{$\begin{array}{c}\text { with fiber laser for } \\
\text { steel } 50 \mathrm{G}\end{array}$} \\
\hline $20 \div 75$ & $9,35 \cdot 10^{10}$ & $20 \div 77$ & $1,16.10^{10}$ \\
\hline $52 \div 103$ & $1,08 \cdot 10^{11}$ & $37 \div 92$ & $1,36.10^{11}$ \\
\hline
\end{tabular}

For marking by evaporation, engraving and cutting, the preliminary working intervals of the speed are (see Fig. 5 - 9):

\begin{tabular}{|c|c|c|c|}
\hline \multicolumn{2}{|c|}{$\begin{array}{c}\text { with CuBr laser } \\
\text { for steel C35 }\end{array}$} & \multicolumn{2}{c|}{$\begin{array}{c}\text { with fiber laser } \\
\text { for steel C35 }\end{array}$} \\
\hline $\boldsymbol{v}, \mathbf{~} \mathbf{m m} / \mathbf{s}$ & $\mathbf{q}, \mathbf{W} / \mathbf{m}^{2}$ & $\begin{array}{c}\boldsymbol{v}, \\
\mathbf{m m} / \mathbf{s}\end{array}$ & $\mathbf{q}, \mathbf{W} / \mathbf{m}^{\mathbf{2}}$ \\
\hline $\mathbf{2 0} \div \mathbf{3 0}$ & $9,35.10^{10}$ & $\mathbf{2 0} \div \mathbf{3 5}$ & $1,16.10^{11}$ \\
\hline $\mathbf{2 0} \div \mathbf{4 7}$ & $1,08.10^{11}$ & $\mathbf{2 0} \div \mathbf{5 2}$ & $1,36.10^{11}$ \\
\hline \multicolumn{2}{|c|}{$\begin{array}{c}\text { with } \mathbf{C u B r} \text { laser } \\
\text { for steel } \mathbf{5 0 G}\end{array}$} & $\begin{array}{c}\text { with fiber laser for } \\
\text { steel } \mathbf{5 0 G}\end{array}$ \\
\hline $\begin{array}{c}20 \div \\
30\end{array}$ & $1,08.10^{11}$ & $20 \div 37$ & $1,36.10^{11}$ \\
\hline
\end{tabular}


Smaller intervals of the speed of steel G50 compared to steel C35 are due to the higher melting and evaporation temperatures of the first steel.

\section{CONCLUSION}

The obtained results will be useful for operators of laser systems to reach the desired optimal technological parameters more quickly. These numerical experiments contribute to significantly reducing the time created in actual production settings. These numerical experiments help to better coordinate the theoretical models of the interaction of laser radiation with specific technological processes related to the melting and evaporation of the materials in the processing area. Experiments are planned to continue to investigate and the impact of other factors influencing the quality of specific technological processes. The aim is to create a basis of technology tables to support pilot real-world experiments in the implementation of new technologies related to the laser processing of different types of materials and ultimately the creation of new products.

\section{References}

[1] Jianmei Li, Aiqun Wang, Yusong Wuab, ZhuoMa, Xinxin Fang, LiangTao, Experimental investigation and mathematical modeling of laser marking two-dimensional barcodes on surfaces of aluminum alloy, Journal of Manufacturing Processes, Volume 21, January 2016, pp 141-152

[2] Valiulin A., Gorniy S., Grechco Y., Patrov M., Yudin K., Yurevich V. Lazerna markirovka materialov. Nauchno-technicheskij zhurnal Fotonika, 2007, 3, pp 16-22 (in Russian)

[3] Dutta Majumdar, J., Laser material processing, International Materials Reviews,56(5-6), November 2011, pp. 341-388

[4] Grigoryan A.G., Shiganov I.N., Misyurov A.I. Technologicheskiye processy lazernoy obrabotki. MGTU im. N.E.Baumana, 2006, pp 665 (in Russian)

[5] Senthilkumar, V., Laser cutting process - A Review International Journal of Darshan Institute on Engineering Research \& Emerging Technologies, Vol. 3, No. 1, 2014

[6] Dyuli U. Lazernaya technologiya I analiz materialov. Mir, Moskva, 1986 (in Russian)

[7] Murzin S., Ilyuchin V. Lazerniye technologii obrabotki materialov. SGAU, Samara, 2006 (in Russian)

[8] Zakayukina L., Bannov V. Vidy i parametri processa lazernoy rezki. Novie informacionniye technologii $\mathrm{v}$ avtomatizirovannih sistemah. IPM im. M.Keldisha. Moskva, 2016, pp 163 - 167 (in Russian)

[9] Lazov L., Angelov N. Osnovi factori, opredyelyaschi kachestvo na markirovkata na metali i splavi. Mezhdunarodna nauchna konfirenciya Amteh`07. Gabrovo, 23-24 noemvri 2007, tom I, pp 102107 (in Bulgarian)

[10] Angelov N. Optimizaciya na procesa markirane s lazerno lichenie na obrazci ot instrumentalna stomana. Disertacionen trud za pridobivane na stepen doktor. TU-Gabrovo, 2011 (in Bulgarian)

[11] Belev I. Sreda za presmyatane na lazerno inducirani temperaturni poleta. Diplomna rabota, TU-Gabrovo, 2009 (in Bulgarian)

[12] www.pulsligth.net

[13] www.axsys.de

[14] www.spilasers.com

[15] www.splav-kharkov.com/main.php 